\title{
Life Effects of Narcolepsy: Relationships to Geographic Origin (North American, Asian or European) and to Other Patient and Illness Variables
}

\author{
Roger Broughton, Quais Ghanem, Yasuo Hishikawa, Yoshiro Sugita, Sonia Nevsimalova \\ and Bedrich Roth
}

\begin{abstract}
SUMMAR Y: A recent questionnaire survey of the life-effects of narcolepsy in 180 patients, 60 each from North American, Asian and European populations, compared to similarly distributed age and sex matched controls, documented multiple and marked effects on work, education, driving, accidents, recreation, personality, memory and other parameters. The data have now been further analysed according to the patients' geographic (culturo-genetic) origin and to a number of other patient and illness variables. The three different geographic populations showed few significant differences for the some 160 life-effects items in the questionnaire. This strongly indicates that these are an integral part of the disease or of the human reaction to it. Most of the few significant population differences appeared cultural in origin (e.g., concerning driving records, personality changes), although a few may possibly reflect genetic differences (e.g., visual problems). Analysis of the pooled data according to respondees' age, sex, age at illness onset, duration of illness and treatment led again to relatively few significant findings. It is concluded that, in general, once the disease has been diagnosed, all the major life effects are present and remain so. The results strongly support the contention that most life-effects are not related to the diagnostic 'tetrad' symptoms themselves but rather to excessive daytime sleepiness, the symptom most resistant to anti-narcoleptic treatment.
\end{abstract}

RÉSUMÉ: Nous avons récemment obtenu des données sur les effets multiples et importants de la narcolepsie sur le travail, l'éducation, la conduite automobile, la récréation, la personnalité, la mémoire et plusieurs autres paramètres. Ces données furent recueillies par questionnaire auprès de 180 patients, dont 60 d'Amérique du Nord, 60 d'Asie et 60 d'Europe et des populations témoins appareillées pour l'âge et le sexe. Nous avons de plus analysé les données quant à l'origine culturo-génétique et géographique des patients ainsi qu'en rapport avec plusieurs autres variables. Les 3 populations géographiquement distinctes ne montrèrent que très peu de différences significatives sur les 160 effets divers étudiès dans le questionnaire. Il semble donc que ces caractéristiques font partie intégrante de la maladie ou de la réaction humaine à cette maladie. La majorité des différences observées s'avéra être d'origine culturelle (conduite automobile, personnalité), même si certains pourraient être d'origine génétique (ex.: problèmes visuels). L'analyse des données regroupées selon l'âge, le sexe, l'âge de début, la durée de la maladie ou du traitement n'a donné que peu d'indices significatifs. En conclusion nous croyons qu'une fois la maladie diagnostiquée, la plupart des effets sur le mode de vie sont déjà présents, et qu'il persistent inchangés. Il semble que la plupart des effets secondaires observés ne sont pas en rapport avec la tétrade symptômatique diagnostique, mais plutôt avec une somnolence diurne excessive, symptôme qui est le plus résistant au traitement anti-narcolepsie.

Can. J. Neurol. Sci. 1983; 10:100-104

Other than for epilepsy, there have been few published studies of the often very serious socio-economic effects of chronic neurological diseases. An initial report based on a questionnaire survey concerning such effects for 43 narcoleptics compared to controls was published by Broughton and Ghanem (1976). We extended this project to an international collaborative controlled study involving patients from centers in Ottawa (Canada), Osaka (Japan), and Prague (Czechoslovakia). It included 180 narcoleptic patients and 180 sex and age (within a year) matched controls distributed equally between the three centers (Broughton et al., 1981). We confirmed that narcolepsy does indeed have serious deleterious effects on work, education, recreation, driving and accidents in general, and is significantly associated with a number of symptoms other than the Yoss and Daly (1957) tetrad which could also be involved in such effects.

The initial report did not consider the life-effects as a function of the patients' geographic origin for possible cultural or genetic aspects or by their age, sex, age at onset of the condition, duration of illness or presence or absence of appropriate treatment. All of these factors might be expected to be associated with major differences in the extent and nature of the life-effects.

\section{METHODS}

The previous paper (Broughton et al., 1981) describes the questionnaire and provides patient details. In brief, the questionnaire included some 160 questions (framed to ensure a positive, negative or 'don't know' response) about the

From the Division of Neurology, University of Ottawa (Canada), Department of Neuropsychiatry, University of Osaka (Japan), and the

Neurology Clinic, Charles University, Prague (Czechoslovakia).

Received September 15, 1982. Accepted for publication February 28, 1983.

Reprint requests to: Dr. R. Broughton, Division of Neurology, Ottawa General Hospital, 501 Smyth Rd., Ottawa, Ontario,

Canada K1H 8 L6. 
various life-effects and possible contributing symptoms. Questionnaires were checked for completeness at the other participating centers before being forwarded to Ottawa for statistical analysis. The 180 narcoleptics comprised 112 males $(62.2 \%)$ and 68 females (37.8\%). The frequency of diagnostic symptoms were: excessive daytime sleepiness $(95.2 \%)$ or more or less irresistible sleep attacks $(92.2 \%)$, plus one or more of cataplexy $(90.0 \%)$, sleep paralysis (47.2\%) and vivid hypnagogic hallucinations (47.2\%). The patients' treatment is also provided in that paper.

Responses were analysed first according to geographic origin. The 3 groups were similar in age distribution and other major descriptors. The data pool was then examined by age ( 4 groups), sex, age of onset ( 3 groups), duration of illness ( 3 groups), and presence or absence of treatment (2 groups). Statistical comparisons applied the nonparametric Chi-squared test to positive responses for each question. For each variable an overall $2 \mathrm{X} 2,3 \mathrm{X} 2$, or $4 \mathrm{X} 2$ analysis was performed, as indicated. If a significant result was obtained in a $4 \times 2$ or $3 \times 2$ analysis, individual Chi-squared tests were subsequently performed for each combination (e.g., North American versus Japanese, North American versus Czech, Czech versus Japanese) to determine where the significance arose. Because of the large number of dependent variables, a conservative significance level of $\mathrm{p}<.002$ was chosen.

\section{RESULTS}

\section{Geographic Origin of the Patients \\ Work}

There were no significant differences between the three geographic groups on any question involving occupation (Table 1). All showed similar high frequencies of work related problems. There were, however, differences concerning the causes (in a check list) to which any job related difficulties were attributed. Czech patients less frequently thought such problems were due to poor concentration and memory problems; and they tended to attribute these problems more frequently to sleepiness or overt sleep attacks.

\section{Education}

There were no significant inter-group differences in the frequency with which their condition began before formal education was over $(41.7 \%, 35.0 \%, 50.0 \%$, respectively for North American, Japanese and Czech populations*). Of these, no significant differences were found in the incidence for which the condition led to poor marks $(52.0 \%, 71.4 \%$, $40.0 \%$ ). The populations also did not differ in level of educational achievement.

\section{Driving}

The proportion of driving narcoleptics was significantly lower in the Czech population (Table 2). Czech narcoleptic drivers fell asleep at the wheel significantly less often than North Americans and nearly significantly less than Japanese; and they had fewer near accidents while driving.

\section{Accidents}

There were no significant differences for frequency of

*Here and subsequently in this section the results are given consecutively for the North American, Asian and Czechoslovakian populations.

\begin{tabular}{|c|c|c|c|c|}
\hline \multicolumn{5}{|c|}{$\begin{array}{l}\text { Table 1: Occupational effects attributed to narcolepsy } \\
\text { compared between the three groups. }\end{array}$} \\
\hline & N. AM. & JAPAN & $\mathrm{CZECH}$ & SIG. \\
\hline Presently working & $73.3 \%$ & $85.0 \%$ & $86.7 \%$ & - \\
\hline Reduced performance & $61.4 \%$ & $68.6 \%$ & $63.5 \%$ & - \\
\hline Fear of job loss* & $45.5 \%$ & $47.1 \%$ & $30.8 \%$ & - \\
\hline Earnings decreased* & $31.8 \%$ & $47.1 \%$ & $36.5 \%$ & - \\
\hline Prevented promotion* & $22.7 \%$ & $35.3 \%$ & $34.6 \%$ & - \\
\hline Job dismissal & $23.3 \%$ & $21.7 \%$ & $16.7 \%$ & - \\
\hline Disability insurance & $8.3 \%$ & $10.0 \%$ & $15.0 \%$ & - \\
\hline \multicolumn{5}{|l|}{ Job difficulties, due to } \\
\hline poor concentration & $56.8 \%$ & $41.2 \%$ & $7.7 \%$ & $\mathrm{C}<\mathrm{J}, \mathrm{NA}$ \\
\hline poor memory & $31.8 \%$ & $45.1 \%$ & $0.0 \%$ & $\mathrm{C}<\mathrm{J}, \mathrm{NA}$ \\
\hline sleep attacks & $70.5 \%$ & $72.5 \%$ & $92.3 \%$ & - \\
\hline personality change & $22.7 \%$ & $13.7 \%$ & $3.8 \%$ & - \\
\hline interpersonal problems & $15.9 \%$ & $37.3 \%$ & $3.8 \%$ & $\mathrm{C}<\mathrm{J}$ \\
\hline
\end{tabular}

Significance between groups by Chi-squared test at $\mathrm{p}<.002$ for this and all subsequent tables. Comparisons are non-significant unless noted. NA $=$ North American, J= Japanese, $\mathrm{C}=$ Czechoslovakian

- percent of presently working respondees.

Table 2: Driving effects related to narcolepsy in the 3 groups

\begin{tabular}{lrrrc}
\hline \hline & N. AM. & JAPAN & CZECH & SIG. \\
Proportion driving & $73.3 \%$ & $51.7 \%$ & $21.7 \%$ & $\mathrm{C}<\mathrm{J}, \mathrm{NA}$ \\
Fell asleep driving* & $72.7 \%$ & $48.4 \%$ & $7.7 \%$ & $\mathrm{C}<\mathrm{NA}$ \\
Cataplexy driving* & $34.1 \%$ & $22.6 \%$ & $0.0 \%$ & - \\
Sleep paralysis driving* & $18.2 \%$ & $22.6 \%$ & $0.0 \%$ & - \\
Frequent accidents* & $34.1 \%$ & $45.2 \%$ & $0.0 \%$ & - \\
Frequent near accidents* & $63.6 \%$ & $61.3 \%$ & $0.0 \%$ & $\mathrm{C}<\mathrm{J}, \mathrm{NA}$ \\
Higher insurance* & $15.9 \%$ & $22.6 \%$ & $7.7 \%$ & - \\
Suspended license & $5.0 \%$ & $10.0 \%$ & $11.7 \%$ & - \\
*of drivers & & & & \\
\hline
\end{tabular}

Table 3: Personality variables compared between the 3 groups

\begin{tabular}{lrrrc}
\hline \hline & N. AM. & JAPAN & CZECH & SIG. \\
Personality change & $70.0 \%$ & $41.7 \%$ & $33.3 \%$ & $\mathrm{C}<\mathrm{NA}$ \\
$\quad$ Preceded & $7.1 \%$ & $4.0 \%$ & $10.0 \%$ & - \\
$\quad$ Followed & $85.7 \%$ & $96.0 \%$ & $90.0 \%$ & - \\
Recurrent depression & $51.7 \%$ & $73.3 \%$ & $31.7 \%$ & $\mathrm{C}<\mathrm{J}$ \\
Obsessive thoughts & $33.3 \%$ & $48.3 \%$ & $10.0 \%$ & $\mathrm{C}<\mathrm{J}$ \\
Large mood swings & $36.7 \%$ & $31.7 \%$ & $23.3 \%$ & - \\
Manic excitement & $20.0 \%$ & $30.0 \%$ & $5.0 \%$ & - \\
Suicidal thoughts & $21.7 \%$ & $10.0 \%$ & $8.3 \%$ & - \\
Had psychotherapy & $26.7 \%$ & $30.0 \%$ & $13.3 \%$ & - \\
Believe extrovert & $53.3 \%$ & $46.7 \%$ & $53.3 \%$ & - \\
Believe introvert & $38.3 \%$ & $46.7 \%$ & $38.3 \%$ & - \\
\hline
\end{tabular}

household and/or occupational accidents attributed to narcolepsy $(48.3 \%, 26.7 \%, 48.3 \%)$. Attributed smoking accidents were significantly less frequent in the Japanese $(43.3 \%, 16.7 \%, 56.7 \%)$.

\section{Recreation}

The 3 populations believed similarly that they obtained "a good amount of exercise" (45.0\%, 31.7\%, 41.7\%). Czech patients answered affirmatively less frequently than both others to the question "Do you have trouble planning exercise" $(46.7 \%, 30.0 \%, 6.7 \%)$. There were no differences for the incidence of sleep attacks during the watching of entertainment, dancing or swimming but North Americans fell asleep more frequently than Czechs or Japanese during card playing $(61.1 \%, 31.7 \%, 28.3 \%)$. 
Table 4: Visual symptoms attributed to narcolepsy compared in the 3 groups

\begin{tabular}{|c|c|c|c|c|}
\hline & N. AM. & JAPAN & $\mathrm{CZECH}$ & SIG. \\
\hline Eye fatigue & $70.0 \%$ & $63.3 \%$ & $8.3 \%$ & $\mathrm{C}<\mathrm{NA}, \mathrm{J}$ \\
\hline Defocusing & $40.0 \%$ & $36.7 \%$ & $13.3 \%$ & $\mathrm{C}<\mathrm{NA}$ \\
\hline Double vision & $43.3 \%$ & $33.3 \%$ & $11.7 \%$ & $C<N A$ \\
\hline Flickering of eyes & $33.3 \%$ & $36.7 \%$ & $5.0 \%$ & $\mathrm{C}<\mathrm{NA}, \mathrm{J}$ \\
\hline \multicolumn{5}{|l|}{ Fluorescent lights } \\
\hline bother eyes & $26.7 \%$ & $5.0 \%$ & $8.3 \%$ & $\mathrm{~J}<\mathrm{NA}$ \\
\hline
\end{tabular}

Table 5: Miscellaneous somatic symptoms attributed to narcolepsy compared for the 3 groups

\begin{tabular}{lrrrc}
\hline \hline & N. AM. & JAPAN & CZECH & SIG. \\
Excessive snoring & $50.0 \%$ & $51.7 \%$ & $25.0 \%$ & - \\
Periodic imbalance & $60.0 \%$ & $35.0 \%$ & $11.7 \%$ & C<NA \\
Easily frustrated & $58.3 \%$ & $21.7 \%$ & $10.0 \%$ & C<NA \\
Marked sensitivity & & & &. \\
$\quad$ to alcohol & $26.7 \%$ & $23.3 \%$ & $36.7 \%$ & - \\
Very easily startled & $40.0 \%$ & $16.7 \%$ & $21.7 \%$ & - \\
Sensations of hot and cold & $41.7 \%$ & $20.0 \%$ & $8.3 \%$ & C $<$ NA \\
Buzzing or ringing in ears & $25.5 \%$ & $20.0 \%$ & $5.0 \%$ & - \\
Sensations of unusual odours & $10.0 \%$ & $1.7 \%$ & $5.0 \%$ & - \\
Sensations of unusual taste & $6.7 \%$ & $3.3 \%$ & $0.0 \%$ & - \\
\hline
\end{tabular}

\section{Personality}

Personality changes (Table 3 ) were attributed to narcolepsy less frequently in Czechs than in North Americans $(70.0 \%, 41.7 \%, 33.3 \%)$. There were no differences in the proportions of those who believed personality changes preceded $(7.1 \%, 4.0 \%, 10.0 \%)$ or followed $(85.7 \%, 96.0 \%$, $90.0 \%$ ) the disease onset. Japanese narcoleptics admitted more frequently to recurrent depression and to ruminating thoughts than Czech patients.

\section{Miscellaneous symptoms}

1. Visual and ocular - Czech narcoleptics had less visual fatigue, recurrent defocusing, diplopia or ocular flickering (Table 4). Fluorescent lighting bothered Japanese narcoleptics less than North Americans.

2. Memory - There were no differences in subjective memory changes between the 3 populations. There were, however, differences for the causes to which patients attributed poorer memory. Czechs more frequently than Japanese thought them to be due to sleepiness or sleep attacks $(66.7 \%, 32.4 \%, 83.3 \%)$ and less frequently than both others to difficulty in concentration $(66.3 \%, 73.0 \%, 25.0 \%)$.

3. Appetite and eating behavior - There were no differences for the frequencies with which narcolepsy was believed associated with eating more or less, or with weight gain or loss. Craving food was significantly more common in North American narcoleptics than both other groups $(66.7 \%, 26.7 \%, 26.7 \%)$; and meals were considered to influence symptoms more frequently in Czechs than in Japanese $(40.0 \%, 23.3 \%, 65.0 \%)$.

4. Sexual effects - There were no differences for any sexual variable including the frequencies with which narcolepsy was associated with lessened sex drive, greater sex drive, impotence in males, or with menstrual or premenstrual effects on symptoms in females.

5. Somatic symptoms - A number of miscellaneous symptoms attributed to the condition were compared (Table 5). Czech patients less frequently than North Americans, had periodic imbalance, ease of frustration, and sensations of 'hot and cold' through the body. Perusal of Table 5 shows that North Americans in general most frequently had accompanying symptoms, a trend also seen for personality changes (Table 3) and visual symptoms (Table 4).

\section{Effects of Age, Sex, Age of Onset, Duration of Illness and Treatment}

Age

Responses were divided into 4 patient age groups at the time of the questionnaire: 29 years and under $(\mathrm{N}=23$, $12.8 \%) ; 30-39$ years $(\mathrm{N}=65,36.1 \%) ; 40-49$ years $(\mathrm{N}=45$, $25.0 \%) ; 50$ and over $(\mathrm{N}=47,26.1 \%)$. Age had no significant effect on the results with one exception; poor memory was attributed to ease of distraction less frequently in the 30-39 year age group than in the 20-and-under or 50-andover groups $(46.7 \%, 3.8 \%, 12.0 \%$, and $44.0 \%$ by increasing age groups). This appears to be a chance finding.

\section{Sex}

Other than questions determined by the patients' sex (i.e., impotence in males and menstrual effects in females), the only variable showing a sex difference was the higher incidence of narcolepsy leading to increased eating in females than males (36.8\% versus $13.4 \%$ ). Others approaching significance $(.002<\mathrm{p}<.01)$ were: higher frequencies for males of working $(88.4 \%$ versus $70.6 \%$ ), driving accidents $(41.3 \%$ versus $12.0 \%)$, suspended license $(13.4 \%$ versus $1.5 \%)$, and sleep paralysis at the wheel $(23.8 \%$ versus $0.0 \%)$.

\section{Age of onset}

Comparisons were made for age of onset of 14 years or less $(\mathrm{N}=33,19.1 \%$ of 173 respondees), 15-29 years $(\mathrm{N}=97,56.1 \%)$, and 30 years and older $(\mathrm{N}=43,24.9 \%)$. Age of onset was a significant determinant for only two questions. As would be expected, narcolepsy began during school significantly less frequently when age of onset was at 30 years or later $(11.6 \%)$ than for age $0-14$ years $(93.9 \%)$ : and reduced sex drive was significantly more frequent with onset at 30 years of age or later (43.6\%) than when up to 14 years of age $(12.0 \%)$ or from $15-29$ years $(11.0 \%)$. Almost significant $(.002<p<.01)$ for late onset narcolepsy was a reduced frequency of accidents in general attributed to the condition $(60.6 \%, 32.3 \%$, and $25.6 \%)$ and increased impotence in males $(6.5 \%, 5.2 \%$ and $22.0 \%)$.

\section{Duration of Illness}

Duration of illness was separated into 3 groups: 9 years or less ( $\mathrm{N}=47,27.2 \%$ of 173 respondees), $10-19$ years $(\mathrm{N}=57,32.9 \%)$ and 20 years or more $(\mathrm{N}=69,39.9 \%)$. Only 6 responses were significant. Narcoleptics of only $0-9$ years duration reported higher frequencies of three visual symptoms than did those of 10-19 years duration; diplopia (53.2\% versus $15.8 \%$ ), defocusing $(46.8 \%$ versus $15.8 \%)$ and visual fatigue $(68.1 \%$ versus $29.8 \%)$. More narcoleptics of 0.9 years duration drove $(66.0 \%)$ than for the 20 year or more group (31.9\%). Not unexpectedly, narcolepsy was present during schooling more frequently in narcolepsy of 
20 years or more duration $(58.0 \%)$ than the $0-9$ year group (19.1\%). Periodic imbalance was significantly more frequent in short duration $(59.6 \%)$ than in medium $(26.3 \%)$ or long duration (26.1\%) narcolepsy. Other strong trends were found. Responses to questions which asked whether or not a particular life-effect had occurred (e.g., work problems, driving problems, accidents) were in general more frequently positive for longer duration narcolepsy. And the nondiagnostic associated symptoms (e.g., memory problems, visual symptoms, impotence in males, snoring, periodic imbalance) were usually noted most often by short duration narcoleptics.

\section{Treatment}

At the time of the questionnaire, 129 patients (71.7\%) were being treated and the remaining $51(28.3 \%)$ were untreated. To our surprise, the presence or absence of treatment did not significantly affect any of the answers, whether involving life-effects or the non-diagnostic associated symptoms. The responses were then reanalysed according to whether the patients had ever been treated $(148,82.2 \%)$ or not $(32,17.8 \%)$. Again, there were no significant differences.

\section{DISCUSSION}

The previous paper (Broughton et al., 1981) documented the pervasive effects of narcolepsy upon work, education, driving, accidents, recreation, personality and interpersonal relationships, and discussed their possible relationships to excessive daytime sleepiness, the diagnostic symptomatic tetrad (sleep attacks, cataplexy, sleep paralysis and vivid hypnagogic hallucinations), or associated symptoms involving vision, memory, or other. A part from a report exclusively on driving by Bartels and Kusakloglu (1955) and our preliminary results in 43 patients (Broughton and Ghanem, 1976), it is the only controlled study of these marked features of the condition.

The further analysis of the data by geographic origin permits at least partial interpretation of the extent to which they may be attributable to cultural or to genetic factors. It is known that important genetic factors exist in idiopathic narcolepsy (Nevsimalova-Bruhova and Roth, 1972; Kessler et al., 1974; Baraister and Parkes, 1978) and that truly familial forms may occur. Our main finding is that relatively few questionnaire items showed significant differences between populations. This indicates that the main life-effects and associated symptoms occur whatever the cultural milieu or genetic pool. They appear to represent an inherent and integral part of the disease and/or of the human reaction to it.

Nevertheless, some significant differences did occur and deserve comment. There was a strong trend for North American and Japanese, compared to Czech, patients to attribute life effects more frequently to problems of concentration or other non-diagnostic symptoms and less frequently to sleepiness or overt sleep attacks (which could cause the former). This is encountered, for instance, in the response to questions concerning difficulties at work or with memory. Such differences of attribution would seem to reflect social rather than genetic differences.

The less frequent driving problems in Czech patients also appear culturally dependent. In Czechoslovakia very stringent laws and enforcement of them exist against driving by narcoleptics, so that the diagnosis leads rapidly to loss of licence. The duration of driving in Czech narcoleptics after diagnosis was, therefore, almost certainly briefer, and presently driving Czech narcoleptics undoubtedly had milder forms of the illness. This would also explain the reduced occurrence of major symptoms at the wheel and of near car accidents for driving Czechs. Finally, similar cultural differences probably explain the more common presence of depression and obsessive thoughts in Japanese patients. It is known that, at least amongst neurotic patients, depression and obsessive reactions are particularly frequent in Japan.

Some of the inter-group differences may, however, at least in part reflect genetic factors. It would be very hard to explain the lower incidence in Czechs of such seemingly objective symptoms as ocular flickering, double vision, or visual blurring by cultural effects. Further clarification of possible genetic differences would involve comparative studies of individual family trees from the three populations and cannot come from the data gathered in the present survey.

Patient age, sex, the age at onset, the duration of the condition, and presence or absence of treatment had all been expected to have a major influence on the results. However, exceedingly few responses were determined by these variables. This further strengthens our belief that the socioeconomic effects and associated symptoms are integral aspects of the disease. In general, all of the major life effects are present and remain present once the condition appears.

The few significant findings can generally be given quite simple interpretations. Thus, the greater incidences of driving accidents and of suspended licence in males would appear to reflect their overall poorer records in the driving population. Reduced sex drive and, almost significantly, increased impotence in males were attributed to narcolepsy, when the condition began later in life, i.e., when these symptoms are already more current. And associated symptoms were more commonly noted in narcolepsy of recent onset, when they would have greater novelty.

The relationship between treatment and reported lifeeffects requires particular consideration. This was the only category which did not at all influence life effects or the presence or absence of associated symptoms. Most of the patients were on traditional antinarcoleptic medication combining some form of REM-sleep suppressant therapy (tricyclic or MAOI medication) with stimulants. The questionnaire did not ask for each question whether or not any improvement was noted after treatment was begun (if treated). The findings must therefore be interpreted with caution. Nevertheless, whether or not patients were on such medication, had been so previously to answering the questionnaire but were not at the time, or had ever been treated, the responses were essentially the same.

It has in fact been our general clinical impression that existing treatments may lead to some improvement in the quality of life of our narcoleptics but certainly do not normalize them in any sense of the word. Although appropriate treatment can suppress the tetrad symptoms, there is almost always substantial residual excessive daytime sleepiness. 
The latter represents the symptom most refractory to treatment (Guilleminault and Dement, 1974; Broughton and Mamelak, 1979). As suggested elsewhere (Broughton, 1976), it may be due to a co-existent sub-vigilance (subwakefulness) syndrome (Roth, 1957; Mouret et al., 1972) involving impaired waking (arousal) mechanisms, in addition to the known abnormal sleep mechanisms.

The lack of correlation between life effects and treatment is further support for the contention that most of the life effects are attributable to such excessive daytime sleepiness rather than to the major tetrad symptoms, which respond much more favorably to medication. Very similar life effects were documented for idiopathic hypersomnia (Broughton et al., 1980) and no doubt would also be found for other neurological causes of excessive daytime sleepiness, such as sleep-related rhythmic leg movements ('nocturnal myoclonus') and sleep apnea syndrome.

Although reduced alertness or excessive daytime sleepiness as a neurological symptom greatly interested classical neurologists such as Sir Henry Head (1923), who considered it a form of impaired vigilance, this symptom subsequently went out of favor. This period of reduced neurological interest in the relatively non-specific general functions of the brain related to maintenance of alertness and attention appears to have paralleled one of increased emphasis on the localizing functions. There is recent evidence, however, for qualitatively different types of neurologically impaired alertness of different pathophysiological mechanisms (Broughton, 1982). The time now appears ripe for analysis of the many clinical forms of reduced daytime alertness, its multiple physiological and neurochemical mechanisms and, where possible, its improvement by more effective therapy.

\section{Acknowledgements}

The authors would like to thank Janet Roberts for her work on the statistical analyses and Barbara Reynolds for typing the manuscript. The project was supported by a grant from the Medical Research Council of Canada, of which Dr. Broughton is a Career Investigator.

\section{References}

Baraister, M. and Parkes, J.D. (1978). Genetic study of the narcolepsy syndrome. J. Med. Genetics, 15, 254-259.

Bartels, E.C. and Kusaklioglu, O. (1965). Narcolepsy: a possible cause for automobile accidents. Labey Clin. Found. Bull., 1412-1426.

Broughton, R. Discussion. In: Narcolepsy, edited by C. Guilleminault, W.C. Dement and P. Passouant. Spectrum: New York, 1976:667.

Broughton, R. (1982). Performance and evoked potential measures of various states of sleepiness. Sleep, 5 (suppl.); 135-146.

Broughton, $R$. and Ghanem, $Q$. The impact of compound narcolepsy on the life of the patient. In: Narcolepsy, edited by C. Guilleminault, W.C. Dement and P. Passouant. Spectrum: New York, 1976:201-220.

Broughton, R. and Mamelak, M. (1979). The treatment of narcolepsy-cataplexy with noctural gamma-hydroxybutyrate. Can. J. Neurol. Sci., 6:1-6.

Broughton, R., Ghanem, Q., Hishikawa, Y., Sugita, Y., Nevsimalova, S. and Roth, B. (1981). Life effects of narcolepsy in 180 patients from North America, Asia and Europe compared to matched controls. Can. J. Neurol. Sci., 8:299-304.

Broughton, R., Nevsimalova, S. and Roth, B. The socio-economic effects of idiopathic hypersomnia - comparisons with controls and with compound narcoleptics. In: Sleep 1978, Fourth European Congress on Sleep Research, edited by L. Popoviciu, B. Asgian and G. Basiu, Karger: Basel, 1980:229-233.

Guilleminault, C. and Dement, W.C. Pathologies of excessive sleep. In Advances in Sleep Research, edited by E. Weitzman, Spectrum: New York. 174:3;345. 390.

Head, H. (1923). The conception of nervous and mental energy. II. Vigilance: a physiological state of the nervous system. Br. J. Psychol., 14:126-147.

Mouret, J.R., Renaud, B., Quenin, P., Michel, D. and Schott, B. (1972). Monoamines et régulation de la vigilance 1 . Apport et interpretation biochemique des données polygraphiques. Rev. Neurol. (Paris), 172, 139-155.

Nevsimalova-Bruhova, S. and Roth, B. (1972). Heredofamilial aspects of narcolepsy and hypersomnia. Arch. Suisses Neurol. Neurochir. Psychiat. 100, 45-54.

Roth, B. (1957). L'activité de sommeil dans l'EEG comme indicateur d'une insuffisance chronique de l'état de vigilance. Electroencephalogr. Clin. Neurophysiol, Suppl 7, 309-311.

Yoss, R.E. and Daly, D.D. (1957). Criteria for diagnosis of the narcolepsy syndrome. Proc. Mayo Clin., 32, 320-328. 